\title{
A STUDY OF IMPACT CRUSHING UNDER REDUCED PRESSURE
}

\author{
HITOSHI HASHIMOTO, TATSUO SHINOZAKI AND SABURO YASHIMA \\ Research Institute of Mineral Dressing and Metallurgy, Tohoku University, Sendai 980
}

\author{
Key Words: Size Reduction, Impact Crushing, Single Particle Crushing, Grinding Mechanism, Hammer \\ Mill, Reduced Pressure
}

\begin{abstract}
Grinding tests on brittle materials were carried out both under reduced pressure and under atmospheric pressure, using a laboratory hammer mill and a vacuum vessel. Finer products were obtained under reduced pressure than under atmospheric pressure.

To explain the experimental results from the standpoint of single fracture, a model calculation was carried out by using a simplified model of the hammer mill. In the model calculation, the friction drag of air, the effect of atmospheric pressure on the strength of brittle particles, the dependence of Young's modulus, Poisson's ratio and the strength on the loading rate, and the dependence of the strength on the particle's volume were taken into account. It was found that a part of the experimental results was explained by the model calculation.
\end{abstract}

\section{Introduction}

A hammer mill is a well-known, representative impact crusher. Its grinding mechanism is presumed to fracture a large particle by collision with rotating hammers. A small particle is, however, supposed to be fractured by collision not only with the hammers but also with the other particles which have already been accelerated by the rotating hammers or by an air stream produced by the rotating hammers. Relative impact velocity of these particles is reduced by the friction drag of air until the collision occurs. Since the effect of the friction drag of air on the reduction of relative impact velocity is larger for small particles than for large ones, it is expected that, in comparison. with grinding under atmospheric pressure, finer products can be obtained by grinding under reduced pressure, where the friction drag of air is negligible.

It was shown by Tanaka et al.$^{6)}$ that finer products were obtained by impact crushing under low pressure. In grinding tests using a simplified impact crusher and a vacuum vessel, they investigated the effect of the friction drag of air, pressure of the atmosphere and particle size on crushing efficiency.

In this study, grinding tests on brittle materials were carried out both under reduced pressure and under atmospheric pressure, using a laboratory hammer mill and a vacuum vessel. In addition, a model calculation was made in order to explain the experimental results from the standpoint of single fracture, by using a simplified model of the hammer mill.

Received July 10, 1986. Correspondence concerning this article should be addressed to H. Hashimoto. T. Shinozaki is now with Idemitsu Petrochemical Co., Ltd., Tokyo
100.

\section{Sample and Experimental Apparatus and Procedure}

Three kinds of brittle materials were used in this work: limestone, marble and gypsum. These samples were prepared by sieving, using a $2^{1 / 2}$ or $2^{1 / 4}$ series of JIS style standard sieves, after grinding by a ball mill. The density, Mohs' hardness, Young's modulus and Poisson's ratio of the samples are tabulated in Table 1. The values of Young's modulus and Poisson's ratio in the table were measured under a conventional rate of loading.

A laboratory hammer mill with a screen was used for grinding tests. The mill has six swing hammers, and their peripheral speed was regulated to $60 \mathrm{~m} / \mathrm{s}$. Grinding tests were carried out both under atmospheric and under reduced pressure. The latter tests were conducted by putting the mill into a vacuum vessel. The pressure in the vessel was 4.3 to $14.7 \mathrm{~Pa}$ by Pirani gauge during the tests. A 500-g sample was fed into the mill at rates of 0.5 to $2.5 \mathrm{~g} / \mathrm{s}$ by a screw feeder. Ground products were collected through a screen having round openings $1 \mathrm{~mm}$ in diameter. New surface area produced by grinding was determined as the difference in the specific surface area between the feed and the products by a permeability method.

\section{Experimental Results}

Experimental results such as new specific surface area produced by grinding under reduced pressure $\Delta S w_{v}$, that under atmospheric pressure $\Delta S w_{a}$, their ratio $\Delta S w_{v} / \Delta S w_{a}$ and average size of the feed are presented in Table 2. As shown in the table, $\Delta S w_{v}$ is larger than $\Delta S w_{a}$ in all experiments, and their ratio is larger for small particles than for large ones. It is, 
Table 1. Properties of samples

\begin{tabular}{|c|c|c|c|c|c|}
\hline Sample & $\begin{array}{c}\text { Density } \\
\rho \\
{\left[\mathrm{kg} / \mathrm{m}^{3}\right]}\end{array}$ & $\begin{array}{c}\text { Mohs' } \\
\text { hardness } \\
H \\
{[-]}\end{array}$ & $\begin{array}{c}\text { Young's } \\
\text { modulus* } \\
Y \\
{[\mathrm{~Pa}]}\end{array}$ & $\begin{array}{c}\text { Poisson's } \\
\text { ratio* } \\
y \\
{[-]}\end{array}$ & $\begin{array}{c}\text { Sphere compressive } \\
\text { strength }^{* *} \\
S_{s} \\
{[\mathrm{~Pa}]}\end{array}$ \\
\hline Limestone & $2.70 \times 10^{3}$ & 4 & $6.80 \times 10^{10}$ & 0.32 & $4.32 \times 10^{6}$ \\
\hline Marble & $2.70 \times 10^{3}$ & 3 & $5.34 \times 10^{10}$ & 0.30 & $3.11 \times 10^{6}$ \\
\hline Gypsum & $2.30 \times 10^{3}$ & 2 & $3.78 \times 10^{10}$ & 0.32 & $2.77 \times 10^{6}$ \\
\hline
\end{tabular}

* Measured under the conventional rate of loading by using cylindrical specimens having a diameter of $2.0 \mathrm{~cm}$ and a length of $4.0 \mathrm{~cm}$.

** Measured under the conventional rate of loading by using spherical specimens having a diameter of $2.0 \mathrm{~cm}$.

Table 2. Experimental results

\begin{tabular}{|c|c|c|c|c|c|c|}
\hline \multirow{2}{*}{ Sample } & \multirow{2}{*}{$\begin{array}{l}\text { Average particle } \\
\text { size of feed } \\
\\
d \\
{[\mathrm{~m}]}\end{array}$} & \multicolumn{2}{|c|}{$\begin{array}{l}\text { New specific surface area } \\
\text { produced by grinding }\end{array}$} & \multirow[b]{2}{*}{$\begin{array}{c}\Delta S w_{v} / \Delta S w_{a} \\
{[-]}\end{array}$} & \multirow[b]{2}{*}{$\begin{array}{l}S_{s_{v}} / S_{s_{a}} \\
{[-]}\end{array}$} & \multirow[b]{2}{*}{$\begin{array}{c}\left(S_{s_{v}} / S_{S_{a}}\right)^{5 / 3} \\
{[-]}\end{array}$} \\
\hline & & $\begin{array}{c}\text { under reduced } \\
\text { pressure } \\
\Delta S w_{v} \\
{\left[\mathrm{~m}^{2} / \mathrm{kg}\right]}\end{array}$ & $\begin{array}{c}\text { under atmospheric } \\
\text { pressure } \\
\Delta S w_{a} \\
{\left[\mathrm{~m}^{2} / \mathrm{kg}\right]}\end{array}$ & & & \\
\hline \multirow[t]{2}{*}{ Limestone } & $1.41 \times 10^{-3}$ & $3.11 \times 10^{2}$ & $2.33 \times 10^{2}$ & 1.34 & \multirow[t]{2}{*}{$1.18^{*}$} & \multirow[t]{2}{*}{1.32} \\
\hline & $4.60 \times 10^{-5}$ & $3.96 \times 10^{2}$ & $2.87 \times 10^{2}$ & 1.38 & & \\
\hline Marble & $9.12 \times 10^{-4}$ & $3.04 \times 10^{2}$ & $2.00 \times 10^{2}$ & 1.52 & $1.25^{*}$ & 1.45 \\
\hline \multirow{4}{*}{ Gypsum } & $1.41 \times 10^{-3}$ & $4.24 \times 10^{2}$ & $3.43 \times 10^{2}$ & 1.24 & \multirow[t]{4}{*}{$1.05^{* *}$} & \multirow[t]{4}{*}{1.08} \\
\hline & $7.11 \times 10^{-4}$ & $4.91 \times 10^{2}$ & $4.06 \times 10^{2}$ & 1.21 & & \\
\hline & $1.78 \times 10^{-4}$ & $7.34 \times 10^{2}$ & $5.77 \times 10^{2}$ & 1.27 & & \\
\hline & $4.60 \times 10^{-5}$ & $4.16 \times 10^{2}$ & $3.02 \times 10^{2}$ & 1.38 & & \\
\hline
\end{tabular}

therefore, concluded that finer products would be obtained by grinding under reduced pressure than under atmospheric pressure.

\section{Model Calculation}

A simplified model of the hammer mill, shown in Fig. 1, was considered to explain the experimental results. The model consists of two regions, one the region of rest into which particles are fed, the other the region of air stream in which the hammers and particles move at the same speed in the same direction as the air stream. The region of air stream has the same width as the hammers. Particles fed into the region of rest dive into the region of air stream and are accelerated due to the friction drag of air. During acceleration, some of the fed particles will collide with particles which are moving in this region at the same velocity $u_{0}$ as the air stream, and others will collide with the hammers. The model is transformed into the following by fixing coordinates on the moving hammer. That is, fed particles having an initial velocity $u_{0}$ and a diameter $d$ dive into the region of rest in which stationary particles are dispersed, as shown in Fig. 2. The speed of the fed particles is reduced due to the friction drag of air, and they collide with the

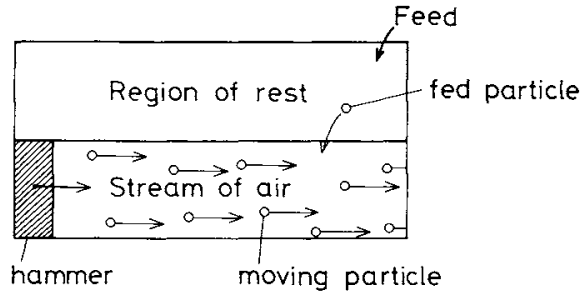

Fig. 1. Simplified model of hammer mill.

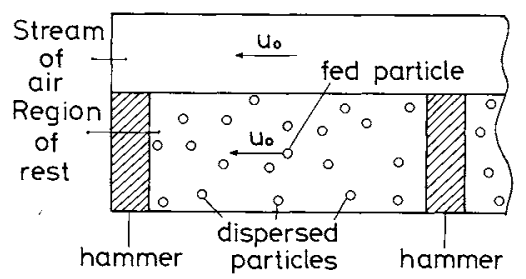

Fig. 2. Equivalent model of hammer mill.

stationary particles or the hammers during deceleration. Mean free path $\bar{S}$ of the fed particles until the first collision occurs is given by the following equation (see Appendix A):

$$
\bar{S}=\frac{d}{6(1-\varepsilon)}
$$


where $\varepsilon$ is the void fraction in the hammer mill. According to Rumpf, ${ }^{5)}$ the value of $(1-\varepsilon)$ in impact crushers ranges from $10^{-2}$ to $10^{-3} \cdot \bar{S}$ is therefore given as

$$
\bar{S} \cong 20 d-200 d
$$

In this study, $\bar{S}$ was assumed to be 100 times the diameter of the particle. All the fed particles were assumed to dive into the region of rest at a middle point in a space between two rotating hammers and to have a mean free path which is 100 times their diameter. Since the distance between two hammers is $60 \mathrm{~mm}$, all the fed particles more than $0.3 \mathrm{~mm}$ in size collide with a hammer.

Under reduced pressure, however, all the fed particles were assumed to collide with the hammers at the impact velocity $u_{0}$, because of negligible friction drag of air stream in the mill.

Impact of two elastic bodies can be described by using the equation of motion and theory of elasticity, assuming that the elastic bodies were in static condition even under impact loading. The relationship between deformation $\Delta$ and the compressive load $L$ acting between the two elastic bodies at a contact surface during impact is given by the following equation, which was obtained by modifying the expression of Timoshenko ${ }^{7)}$ :

$$
\Delta=K L^{2 / 3}
$$

where

$$
K=0.825\left(\frac{r_{1}+r_{2}}{r_{1} r_{2}}\right)^{1 / 3} \cdot\left(\frac{1-v_{1}^{2}}{Y_{1}}+\frac{1-v_{2}^{2}}{Y_{2}}\right)^{2 / 3}
$$

In Eq. (4), $r_{1}$ and $r_{2}$ denote radii of curvature of the elastic bodies at the contact point, $Y_{1}$ and $Y_{2}$ Young's moduli, and $v_{1}$ and $v_{2}$ Poisson's ratios. The equation of motion for the two bodies is given as

$$
M_{r} \frac{d^{2} \Delta}{d t^{2}}=-L
$$

where $M_{r}$ denotes reduced mass and is given by the equation

$$
M_{r}=M_{1} M_{2} /\left(M_{1}+M_{2}\right)
$$

In Eq. (6), $M_{1}$ and $M_{2}$ denote masses of the bodies. The relation between the impact velocity $u$ and the maximum compressive load $L_{\max }$ during impact is given by the following equation, which was obtained by combining Eqs. (3) and (5):

$$
u=0.894 M_{r}^{-1 / 2} K^{1 / 2} L_{\text {max }}^{5 / 6}
$$

The loading duration $t_{\max }$ at maximum compression is given by the equation

$$
t_{\max }=\frac{\Delta_{\max }}{u} \int_{0}^{1}\left(1-x^{5 / 2}\right)^{-1 / 2} d x=1.47 \frac{\Delta_{\max }}{u}
$$

where $A_{\max }$ is the deformation at maximum compression and $x$ is a variable. $t_{\text {max }}$ corresponds to half the loading duration which Timoshenko ${ }^{7}$ described in his article. The rate of loading the bodies $\dot{v}$ at maximum compression is therefore given by the equation

$$
\dot{v}=L_{\max } / t_{\max }=1.47 u L_{\max } / \Delta_{\max }
$$

The relationship between $v$ and $u$ is given by Eq. (10), by combining Eqs. (3), (7) and (9):

$$
\dot{v}=0.711 M_{r}^{1 / 5} K^{-6 / 5} u^{7 / 5}
$$

According to studies of single fracture, Young's modulus, Poisson's ratio and the strength of brittle materials, which were used in this work, vary with the loading rate. The dependence of Young's modulus and Poisson's ratio on the loading rate, which was investigated by Yashima et al., ${ }^{11)}$ is expressed by the following empirical formulas:

$$
\begin{aligned}
& Y=Y_{0}\left(\dot{v} / \dot{v}_{o}\right)^{\alpha} \\
& y=v_{0}\left(\dot{v} / \dot{v}_{0}\right)^{\beta}
\end{aligned}
$$

where $\dot{v}_{0}$ is a standard loading rate, $\alpha$ and $\beta$ are exponents, and $Y_{0}$ and $v_{0}$ are the value of $Y$ and $v$ at $\dot{v}=\dot{v}_{0}$ respectively. The constants in these formulas are presented in Tables 3 and $\mathbf{4}$.

As for the dependence of the sphere compressive strength $S_{s}$, which corresponds to tensile strength, eight kinds of brittle materials were also investigated by Yashima $e t a l{ }^{8)}$ The empirical formula between $S_{s}$ and $\dot{v}$ is given by the equation

$$
S_{s}=S_{s_{0}}\left(\dot{v} / \dot{v}_{0}\right)^{y}
$$

where $\gamma$ is an exponent and $S_{s_{0}}$ is the value of $S_{\mathrm{s}}$ at $\dot{v}=\dot{v}_{0}$.

Furthermore, $S_{s}$ depends on the brittle particle's volume $V$. Its dependence is expressed by the empirical formula ${ }^{10)}$

$$
S_{s}=A V^{-1 / m}
$$

where $A$ is a constant and $m$ is Weibull's coefficient of uniformity.

The relation between $S_{s}$ and fracture load $L_{f}$ is given by the following equation, proposed by Hiramatsu et $a l .{ }^{3)}$;

$$
S_{\mathrm{s}}=2.8 L_{f} / \pi d^{2}
$$

Equations (13), (14) and (15), which were obtained from the compression of spherical specimens between two parallel loading platens, were assumed to apply to the case where a particle was loaded on one side. Equations (11), (12), (13) and (14) were assumed to be extrapolated when the loading rate or the particle's volume was out of its applicable range.

According to Kuwahara, ${ }^{4)}$ the probability of breakage $p_{f}$ of a brittle particle having an average fracture 
Table 3. Empirical formulas for dependence of Young's modulus on loading rate ${ }^{(1)}$ $Y=Y_{0}\left(\dot{v} / \dot{v}_{0}\right)^{\alpha} \quad[\mathrm{Pa}]$

\begin{tabular}{|c|c|c|c|c|}
\hline Sample & $\begin{array}{c}Y_{\mathrm{o}} \\
{[\mathrm{Pa}]}\end{array}$ & $\stackrel{\alpha}{[-]}$ & $\begin{array}{l}\text { Probable } \\
\text { error } \\
{[\mathrm{Pa}]}\end{array}$ & $\begin{array}{c}\text { Range of loading } \\
\text { rate, } \dot{v} \\
{[\mathrm{~N} / \mathrm{s}]}\end{array}$ \\
\hline Quartz glass & $5.15 \times 10^{10}$ & $6.81 \times 10^{-2}$ & $5.55 \times 10^{9}$ & $1.63 \times 10^{1}-4.10 \times 10^{7}$ \\
\hline Borosilicate glass & $5.02 \times 10^{10}$ & $6.65 \times 10^{-2}$ & $4.60 \times 10^{9}$ & $1.63 \times 10^{1}-5.95 \times 10^{7}$ \\
\hline Quartz & $6.13 \times 10^{10}$ & $8.00 \times 10^{-2}$ & $1.12 \times 10^{10}$ & $8.17-1.80 \times 10^{7}$ \\
\hline Feldspar & $3.59 \times 10^{10}$ & $7.47 \times 10^{-2}$ & $5.40 \times 10^{9}$ & $-1.79 \times 10^{7}$ \\
\hline Limestone & $8.89 \times 10^{10}$ & $1.37 \times 10^{-2}$ & $1.17 \times 10^{9}$ & $-5.12 \times 10^{6}$ \\
\hline Marble & $5.77 \times 10^{10}$ & $1.00 \times 10^{-3}$ & $4.80 \times 10^{8}$ & $-1.79 \times 10^{6}$ \\
\hline Gypsum & $3.08 \times 10^{10}$ & $3.20 \times 10^{-2}$ & $2.91 \times 10^{8}$ & $-3.09 \times 10^{6}$ \\
\hline Talc & $2.24 \times 10^{10}$ & $4.02 \times 10^{-2}$ & $2.44 \times 10^{9}$ & $-1.39 \times 10^{6}$ \\
\hline
\end{tabular}

$\dot{v}_{0}=1.63 \times 10^{-1} \mathrm{~N} / \mathrm{s}$.

Table 4. Empirical formulas for dependence of Poisson's ratio on loading rate ${ }^{11}$, $v=v_{0}\left(\dot{v} / \dot{v}_{0}\right)^{\beta} \quad[-]$

\begin{tabular}{|c|c|c|c|c|}
\hline Sample & $\begin{array}{c}y_{0} \\
{[-]}\end{array}$ & $\begin{array}{c}\beta \\
{[-]}\end{array}$ & $\begin{array}{c}\text { Probable } \\
\text { error } \\
{[-]}\end{array}$ & $\begin{array}{l}\text { Range of loading } \\
\text { rate, } \dot{v} \\
{[\mathrm{~N} / \mathrm{s}]}\end{array}$ \\
\hline Quartz glass & $2.01 \times 10^{-1}$ & $-8.50 \times 10^{-3}$ & $2 \times 10^{-3}$ & $1.63 \times 10^{1}-4.10 \times 10^{7}$ \\
\hline Borosilicate glass & $2.49 \times 10^{-1}$ & $-1.53 \times 10^{-2}$ & $1 \times 10^{-3}$ & $1.63 \times 10^{1}-5.95 \times 10^{7}$ \\
\hline Quartz & $1.50 \times 10^{-1}$ & $-2.39 \times 10^{-2}$ & $4 \times 10^{-3}$ & $\begin{array}{ll}8.17 & -1.80 \times 10^{7}\end{array}$ \\
\hline Feldspar & $3.03 \times 10^{-1}$ & $-1.48 \times 10^{-2}$ & $1 \times 10^{-3}$ & $-1.79 \times 10^{7}$ \\
\hline Limestone & $4.11 \times 10^{-1}$ & $-2.12 \times 10^{-2}$ & $2 \times 10^{-3}$ & $-5.12 \times 10^{6}$ \\
\hline Marble & $3.06 \times 10^{-1}$ & $-3.87 \times 10^{-2}$ & $1.4 \times 10^{-2}$ & $-1.79 \times 10^{6}$ \\
\hline Gypsum & $3.25 \times 10^{-1}$ & $-4.30 \times 10^{-3}$ & $2 \times 10^{-3}$ & $-3.09 \times 10^{6}$ \\
\hline Talc & $3.49 \times 10^{-1}$ & $-1.73 \times 10^{-2}$ & $7 \times 10^{-3}$ & $-1.39 \times 10^{6}$ \\
\hline
\end{tabular}

$\dot{v}_{0}=1.63 \times 10^{-1} \mathrm{~N} / \mathrm{s}$.

load $\bar{L}_{f}$ is given by the following equation, when the load $L$ acts on the particle:

$$
p_{f}=1-\exp \left[-\left(L / \tilde{L}_{f}\right)^{2.5}\right]
$$

The effect of the atmosphere on the strength of brittle particles was also considered in this study. $S_{s}$ was measured both under reduced and under atmospheric pressure by Yashima et al. ${ }^{9)}$ at a conventional rate of loading. They found that $S_{s}$ has a tendency to be larger under reduced pressure than under atmospheric pressure. The ratio of the sphere compressive strength under reduced pressure $S_{s_{v}}$ to that under atmospheric pressure $S_{s_{a}}$ is presented in Table 2.

The drag force of air was calculated by using Stokes', Allen's or Newton's law ${ }^{1)}$ governed by the range of Reynolds number.

It was assumed that the effects of the loading rate, particle volume and atmosphere on the crushing behavior of the brittle particle are independent of each other.

\section{Results of Model Calculation}

The probability of breakage of the fed particle, which was calculated for a wide range of particle size, is illustrated in Figs. 3, 4 and 5, for limestone, marble

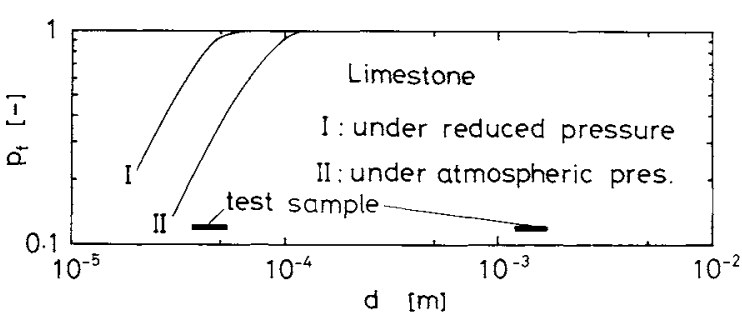

Fig. 3. Relationship between probability of fracture and particle size calculated by using a simplified model (Limestone).

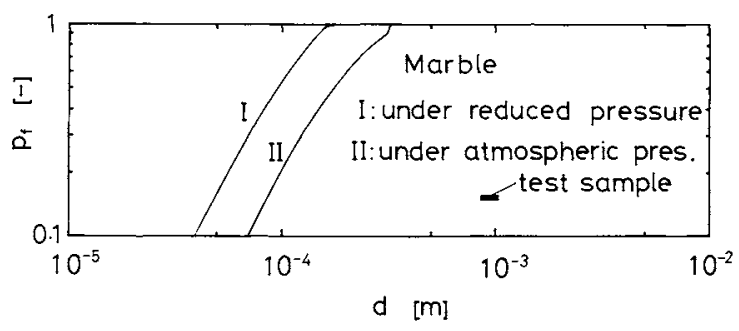

Fig. 4. Relationship between probability of fracture and particle size calculated by using a simplified model (Marble).

and gypsum respectively. From the figures, the probability of breakage of large particles is close to unity whether under reduced or under atmospheric pres- 


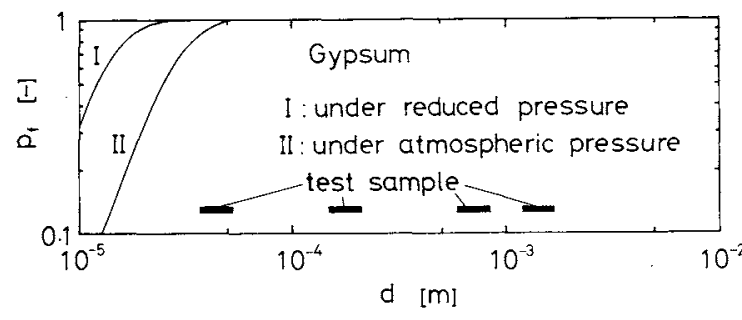

Fig. 5. Relationship between probability of fracture and particle size calculated by using a simplified model (Gypsum).

sure. However, the probability of breakage of particles less than $1 \times 10^{-4} \mathrm{~m}$ for limestone, $4 \times 10^{-4} \mathrm{~m}$ for marble and $5 \times 10^{-5} \mathrm{~m}$ for gypsum under reduced pressure is larger than that under atmospheric pressure. It suggests that fine products can be more readily produced under reduced pressure than under atmospheric pressure.

In single fracture of a brittle particle, specific surface area produced by fracture $\Delta S w$ is in proportion to specific strain energy $E / M$, accumulated in the particle until fracture occurs at the same loading rate. From the theory of elasticity and Eq. (15), $E / M$ is proportional to $S_{s}^{5 / 3}$ (see Appendix B). If the probability of breakage is close to unity and the load on the brittle particle acts at the same loading rate, the ratio of $\Delta S w_{v}$ to $\Delta S w_{a}$ approximately agrees with the value of $\left(S_{s_{v}} / S_{s_{a}}\right)^{5 / 3}$. The value of $\left(S_{s_{v}} / S_{s_{a}}\right)^{5 / 3}$ is also tabulated in Table 2 together with the experimental results of $\Delta S w_{v} / \Delta S w_{a}$. As shown in the table, $\Delta S w_{v} / \Delta S w_{a}$ approximately agrees with the value of $\left(S_{s_{v}} / S_{s_{a}}\right)^{5 / 3}$ for large particles for which the probability of breakage is close to unity, except for gypsum. For small particles, $\Delta S w_{v} / \Delta S w_{a}$ has a tendency to increase with decreasing particle size. This agrees with the results of the model calculation.

\section{Conclusion}

Grinding tests on brittle materials were carried out both under reduced and under atmospheric pressure, using a laboratory hammer mill. Finer products were obtained under reduced pressure than under atmospheric pressure.

In addition, a model calculation was carried out to explain the experimental results from the standpoint of single fracture by using a simplified model of the hammer mill. Results of the model calculation indicated that a part of the experimental results was explained by this model.

\section{Appendix A}

Collision of a fed particle with a stationary particle occurs when the distance between the center of the fed particle and the center of the stationary one equals $d$. The probability of collision of the fed particle with the stationary one, having the free path of $S$ to $S+\Delta S$, is given by the product of two probabilities. One is the probability that no center of a stationary particle is included in a cylindrical space of diameter $2 d$ and length $S$, which was formed along the free path. The other is the probability that only one center is included in an incremental cylinder of length $\Delta S$, as shown in Fig. 6. The probability $p(k ; N V)$ that $k$ centers of stationary particles are included in a space of volume $V$ is given by the following Poisson distribution:

$$
p(k ; N V)=\frac{(N V)^{k}}{k !} \exp (-N V)
$$

where $N$ denotes the number of stationary particles in unit volume, assuming that the stationary particles are dispersed at random in position. Therefore, the probability of the collision $\Delta p$ having the free path of $S$ to $S+\Delta S$, is given by the equation

$$
\begin{aligned}
\Delta p & =p\left(0 ; N \pi d^{2} S\right) p\left(1 ; N \pi d^{2} \Delta S\right) \\
& =N \pi d^{2} \Delta S \exp \left[-N \pi d^{2}(S+\Delta S)\right]
\end{aligned}
$$

The probability density of the collision $p(S)$ having the free path of $S$ is, therefore, given by the equation

$$
\begin{aligned}
p(S) & =\lim _{\Delta S \rightarrow 0} \Delta p / \Delta S \\
& =a \exp (-a S)
\end{aligned}
$$

where

$$
a=N \pi d^{2}
$$

Mean free path $\bar{S}$ is given by the equation

$$
\begin{aligned}
\bar{S} & =\int_{0}^{\infty} S p(S) d S=a \int_{0}^{\infty} S \exp (-a S) d S \\
& =1 / a=1 / N \pi d^{2}
\end{aligned}
$$

$N$ is expressed by using the void fraction $\varepsilon$ and the diameter $d$, as follows:

$$
N=6(1-\varepsilon) / \pi d^{3}
$$

From Eqs. (A-5) and (A-6), the following relationship is obtained:

$$
\bar{S}=d / 6(1-\varepsilon)
$$

\section{Appendix B}

The strain energy $E$ accumulated in a brittle particle until fracture occurs is given by the equation

$$
E=\int_{0}^{\Delta_{f}} L d \Delta
$$

where $A_{f}$ denotes the deformation of the particle at the breaking point. From Eqs. (3) and (B-1), the relation between $E$ and the fracture load $L_{f}$ is given by the equation

$$
E=\int_{0}^{L_{f}} \frac{2}{3} K L^{2 / 3} d L=0.4 K L_{f}^{5 / 3}
$$

From Eqs. (15) and (B-2), $E / M$ is related to $S_{s}$ by the equation

$$
E / M=0.4 K M^{-1}\left(\pi d^{2} / 2.8\right)^{5 / 3} S_{s}^{5 / 3}
$$

where $M$ is the mass of the particle. The following relationship is, therefore, found to be applicable:

$$
E / M \propto S_{s}^{5 / 3}
$$

\section{Nomenclature}

$\begin{array}{ll}A & =\text { coefficient in Eq. (14) } \\ d & =\text { diameter of particle } \\ E & =\text { strain energy (=fracture energy) } \\ E / M & =\text { specific fracture energy } \\ H & =\text { Mohs' hardness }\end{array}$




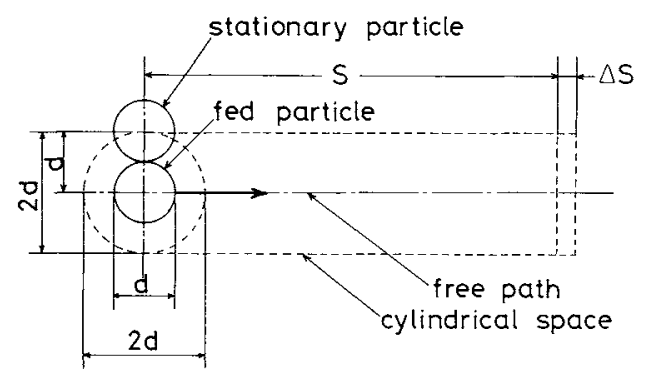

Fig. 6. Cylindrical space formed along free path of fed particle.

\begin{tabular}{|c|c|c|}
\hline$K$ & $=$ coefficient given by Eq. (4) & {$\left[\mathrm{m} \cdot \mathrm{N}^{-2 / 3}\right.$} \\
\hline$k$ & $=$ number of particles & $r$ \\
\hline$L$ & $=$ compressive load & N \\
\hline$L_{f}$ & $=$ fracture load & $\mathrm{T}$ \\
\hline $\bar{L}_{f}$ & $=$ average fracture load & \\
\hline$L_{\max }$ & $=$ load at maximum compression & \\
\hline$M, M_{1}, M_{2}$ & $=$ mass of particle & \\
\hline$M_{r}$ & $=$ reduced mass & \\
\hline$m$ & $=$ Weibull's coefficient of uniformity & \\
\hline$N$ & $=$ number of particles in unit volume & \\
\hline$p_{f}$ & $=$ probability of fracture & \\
\hline$p(k ; N V)$ & $\begin{array}{l}=\text { probability that } k \text { points are included } \\
\text { in a space of volume } V\end{array}$ & \\
\hline$p(S)$ & $\begin{array}{l}=\text { probability density of collision having } \\
\text { free path } S\end{array}$ & {$\left[\mathrm{~m}^{-1}\right]$} \\
\hline$\Delta p$ & $\begin{aligned}= & \text { probability of collision having } \\
& \text { free path of } S \text { to } S+\Delta S\end{aligned}$ & \\
\hline$r_{1}, r_{2}$ & $=$ radius of curvature & \\
\hline$S$ & $=$ free path & \\
\hline $\bar{S}$ & $=$ mean free path & \\
\hline$S_{s}$ & $\begin{aligned}= & \text { sphere compressive strength } \\
& (=\text { tensile strength })\end{aligned}$ & {$[\mathrm{P}$} \\
\hline$S_{s_{0}}$ & $=$ coefficient in Eq. (13) & {$[\mathrm{P}$} \\
\hline$S_{s_{a}}$ & $=S_{s}$ under atmospheric pressure & {$[\mathrm{P}$} \\
\hline$S_{s_{v}}$ & $=S_{s}$ under reduced pressure & \\
\hline$\Delta S$ & $=$ incremental free path & \\
\hline$\Delta S w$ & $\begin{aligned}= & \text { specific surface area produced by fracture } \\
& \text { or grinding }\end{aligned}$ & {$\left[\mathrm{m}^{2} / \mathrm{k}\right.$} \\
\hline$\Delta S w_{a}$ & $=\Delta S w$ under atmospheric pressure & \\
\hline$\Delta S w_{v}$ & $=\Delta S w$ under reduced pressure & {$\left[\mathrm{m}^{2} / \mathrm{k}\right.$} \\
\hline
\end{tabular}

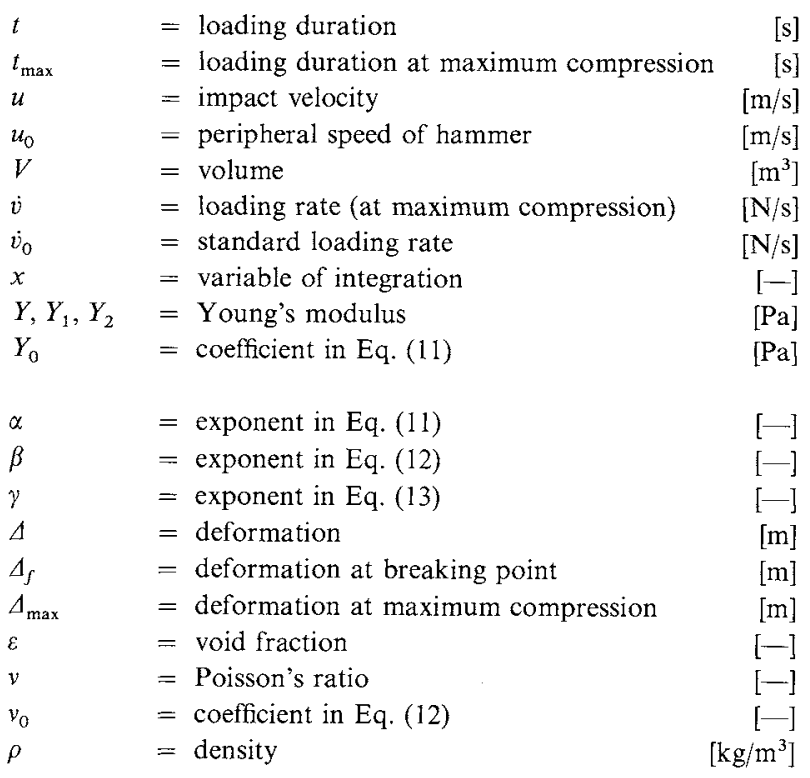

\section{Literature Cited}

1) Hatta, S. and S. Maeda: "Kagaku Kogaku Gairon," p. 272, Kyoritsu, Tokyo (1966).

2) Hayakawa, S.: Master Thesis, Yamagata Univ. (1968).

3) Hiramatsu, Y., Y. Oka and H. Kiyama: Nippon Kogyo Kaishi, 81, 1024 (1965).

4) Kuwahara, Y.: Doctor Thesis, Tohoku Univ., 133 (1985).

5) Rumpf, H.: Chemie-Ing.-Techn., 31, 323 (1959).

6) Tanaka, T., T. Kohata and A. Suzuki: Kagaku Kögaku, 28, 1030 (1964).

7) Timoshenko, S. P. and J. N. Goodier: "Theory of Elasticity," 3rd Edition, p. 420, McGraw-Hill, New York (1970).

8) Yashima, S., F. Saito and H. Hashimoto: submitted to $J$. Chem. Eng. Japan.

9) Yashima, S., F. Saito and T. Mikuni: Kagaku Kogaku Ronbunshu, 2, 150 (1976).

10) Yashima, S., Y. Kanda, T. Izumi and T. Shinozaki: Kagaku Kōgaku, 36, 1017 (1972)

11) Yashima, S., Y. Kanda, T. Sasaki, M. Iijima and F. Saito: Kagaku Kōgaku, 37, 1218 (1973). 